\title{
Article
}

\section{Prevention and management of skin tears in older people}

McInulty, Lorna

Available at http://clok.uclan.ac.uk/18124/

Mclnulty, Lorna (2017) Prevention and management of skin tears in older people. Emergency Nurse, 25 (3). pp. 32-39. ISSN 1354-5752

It is advisable to refer to the publisher's version if you intend to cite from the work. http://dx.doi.org/10.7748/en.2017.e1687

For more information about UCLan's research in this area go to http://www.uclan.ac.uk/researchgroups/ and search for < name of research Group>.

For information about Research generally at UCLan please go to http://www.uclan.ac.uk/research/

All outputs in CLoK are protected by Intellectual Property Rights law, including Copyright law. Copyright, IPR and Moral Rights for the works on this site are retained by the individual authors and/or other copyright owners. Terms and conditions for use of this material are defined in the policies page.

\section{CLoK}

Central Lancashire online Knowledge www.clok.uclan.ac.uk

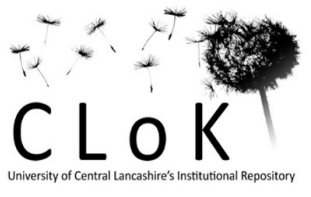




\section{Emergency Nurse}

\section{Skin Tears - current thinking for prevention and management of skin tears in the elderly. --Manuscript Draft--}

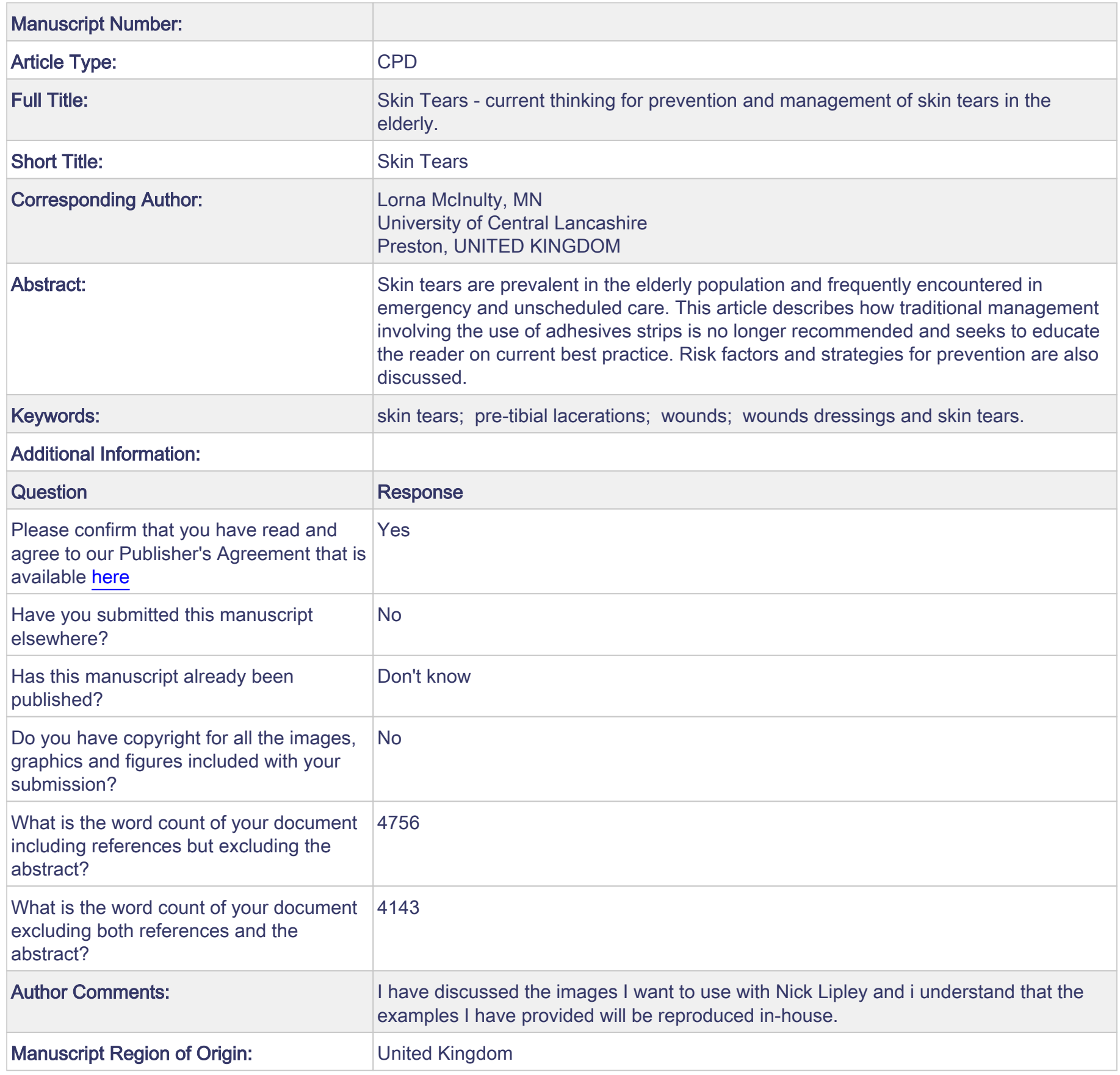




\section{Introduction}

Skin tears are prevalent in the elderly population and are potentially one of the most challenging of wound presentations. It may take considerable clinical skill to successfully achieve healing of these wounds, with either minimal or no complications. The aim of this article, therefore, is to discuss the nature and management of skin tears and to consider current best practice. After reading the article, practitioners should be able to

- recognise the predisposing factors for skin tears and employ suitable prevention strategies

- recall the anatomy, physiology and functions of the skin

- recall the process of wound healing

- recognise the nature of potential complications associated with skin tears.

- understand which dressings are appropriate for managing a skin tear

\section{Prevalence of skin tears}

For many clinical conditions, it is people at the extremes of age who are more vulnerable and this is equally true of skin tears. A skin tear is defined as, "A wound caused by shear, friction and/or blunt forces resulting in separation of skin layers" (Le Blanc and Baranoski 2011). In emergency and primary care settings, skin tears are more commonly associated with the elderly population but they are not, in fact, uncommon amongst neonates and infants whose skin is yet to mature and in whom the epidermis and dermis are not yet fully cohesive (Bianchi 2012). Premature babies, neonates, and infants who require hospital care are particularly at risk from skin trauma caused by invasive devices and the dressings and tapes designed to secure them. Such devices are generally placed in and around the head and face, or in the extremities. Therefore, these are the areas where skin tears are seen in this age group. Paediatric risk factors, however, differ from those of the elderly population where risk 
is related to general frailty, difficulty mobilising and a propensity to fall. In this group of patients, skin tears are often seen in the lower limbs, especially in the pre-tibial region, though also in the forearms and hands. Other people at risk of skin tears include the critically ill or clinically compromised patient, many of whom will coincidentally be elderly, by virtue of the increase in co-morbidities and complex health problems that are common in this group. Chronic hypoxia, poor nutrition and suppressed immunity due to disease are also significant risk factors in all patient groups.

Accurate figures for United Kingdom (UK) prevalence of skin tears are not readily available but a number of UK authors have asserted that many skin tears go unreported (Clothier 2014, All Wales Tissue Viability Forum 2015, Stephen-Haynes and Deeth 2016). It would be reasonable to assume that UK prevalence may be comparable to figures from similarly developed nations with growing elderly populations, such as Australia and the United States. One Australian study found a skin tear prevalence of $8-11 \%$ in in-patents in public hospitals (Mulligan et al 2009) whilst US figures, though now over 10 years old (Baranoski 2005), suggest 1.5 million elderly people sustain skin tears whilst in elderly care facilities. A follow-up to the Australian study (Mulligan et al 2011) suggested an overall 4.3\% increase in skin tears from the 2009 figures. There are more recent figures from small scale studies from the US (Le Blanc and Baranoski 2011) and clinical audit from the UK (Stephen-Haynes et al 2011) but these are confined to the care home setting and therefore not indicative of the true extent of the problem.

Skin tears are certainly not uncommon in practice but what is clearly established is that the development of chronic wounds is strongly related to age (Morgan, 2015). In this context, a chronic wound may be loosely defined as an acute wound that fails to heal within an expected time frame. However, many skin tear wounds can, with appropriate management, be either prevented or resolved. The remainder of this article will concentrate on these aspects of care in relation to the elderly population. 
Time out: thinking about the elderly population, write a list of what you consider to be the main risk factors and causes of skin tears.

\section{$\underline{\text { Risk factors and causes of skin tears }}$}

Readily identifiable causes of skin tears include traumatic removal of wound dressings or surgical tape and blunt force trauma involving falls or wheelchair injuries (Hebert 2016). Health care workers should be aware of the need to adhere to uniform policy as injury to patient skin through long fingernails and inappropriate jewellery have both been identified as further causes of skin tears. Hebert suggests that not all causes are as obvious and that even normal activities such as applying or removing tights and stockings can put vulnerable skin at risk. When these activities are performed by a health care provider or other carer, the risk is magnified. Prevention strategies are therefore very important and much preferable to cure.

Clothier (2014) proposed a number of additional risk factors for skin tears including: age over 75; female sex; history of previous skin tears; cognitive or sensory impairment, including from diabetes and dementia, and visual impairment. Agitation, incontinence and polypharmacy have also been highlighted in the literature (Hebert 2016), polypharmacy meaning four or more prescribed medications in use.

Time out: thinking about both community and hospital environment, what can be done to prevent skin tears?

\section{Prevention}

Health care professionals, both in hospital and community, are in a position to reduce the risk of skin tears. Le Blanc and Baranoski (2011) reported the consensus statement from a group of international wound care experts regarding prevention (see Table 1). 
- Assess for risk on admission to healthcare services and whenever the patient's condition changes.

- Implement a systematic prevention protocol

- Ensure those at risk wear long sleeves, long trousers or knee high socks

- Provide shin guards/leg protectors for those who experience repeat skin tears on shins

- Ensure safe patient handling techniques and equipment/environment

- Involve patents and families in prevention strategies

- Educate nursing staff and caregivers to ensure proper techniques for providing care without causing skin tears

- Consult a dietitian to ensure adequate nutrition and hydration

- Keep skin well lubricated by applying hypoallergenic moisturiser at least twice a day

- Protect people at high risk of trauma during routine care from self-injury

(Le Blanc and Baranoski 2011)

Prevention should start with early identification of those at risk (Bianchi, 2012). Many prevention strategies amount to 'common sense' but may nevertheless be neglected by elderly people. Therefore, it is incumbent upon all professionals who interact with the elderly to advise on potential hazards. Trip hazards, for example, are very common and include loose footwear, uneven carpeting and scatter rugs. Areas within the home which patients frequently traverse should be clutter free e.g. from living room to kitchen, bedroom to bathroom, and so on. Sharp-edged furniture should be padded for patient protection. Healthcare professionals must properly utilise moving and handling equipment to further protect patients.

Many well established charities such as Age Concern and Age UK can visit and advise elderly people about practical falls prevention and some emergency departments (EDs) have close links and easy referral systems to these organisations. Referral for 'at risk' individuals can also be made to community falls teams which usually include an occupational therapist and a social worker. These teams can provide grab rails, properly-fitting footwear and other aids or assistance, as appropriate. Currently within ambulance services there is also momentum to promote falls prevention by increasing the number of referrals to falls teams and ultimately reducing conveyance to hospital. 
Paramedics, like district nurses, are well-placed to risk-assess a patient's home environment and in some areas of the country paramedics are formally included in falls teams. Falls prevention schemes have been seen to contribute to preserving both patients' independence and dignity (Pyer et al 2015).

\section{Anatomy and Physiology}

Despite prevention strategies, skin tears may still occur. When assessing or managing such wounds, it is important to recall the anatomy and physiology of the skin.

Time out: Look at figure no. 1 Try to label the layers and structures of the skin.

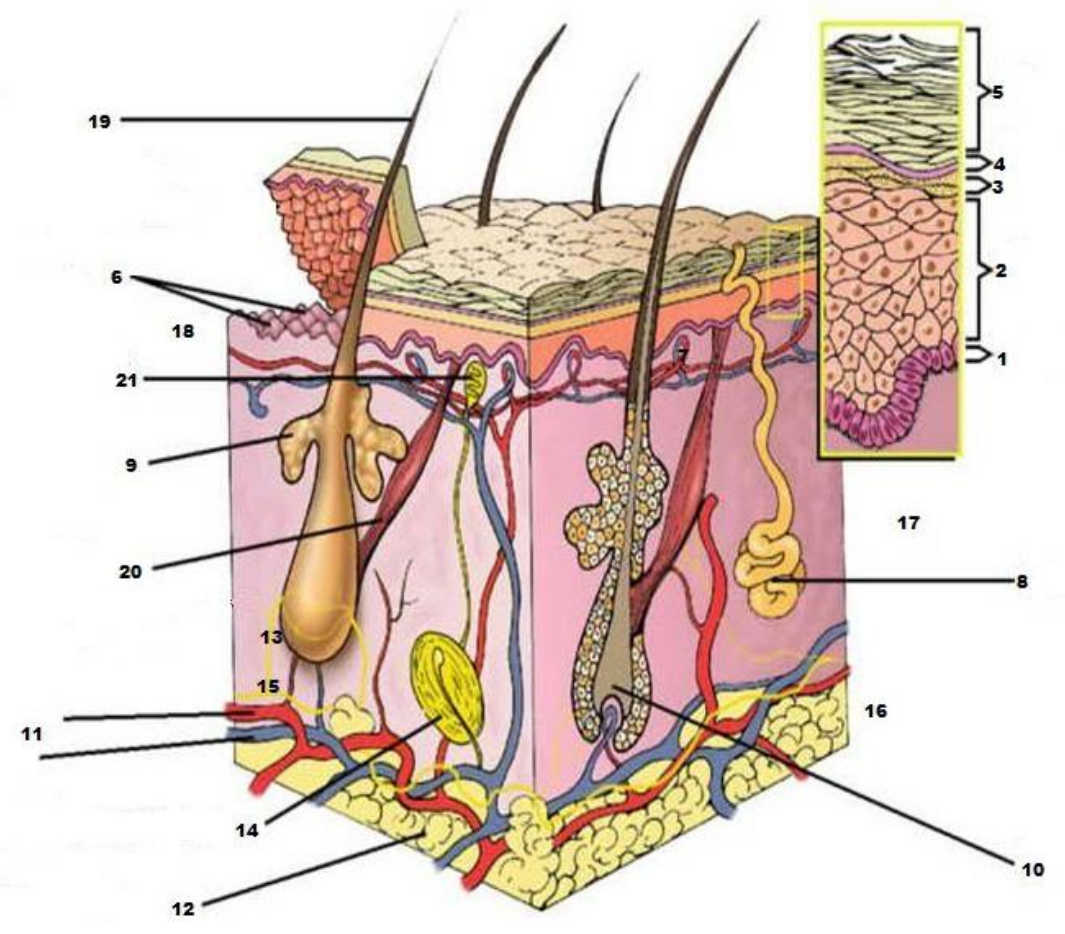

Figure 1 https://www.sporcle.com/games/Elektra/skinstructure

The skin consists of three layers - the epidermis, the dermis and the subcutaneous layer (also known as the hypodermis). The epidermis is roughly a tenth of a millimetre thick yet consists of 5 individual layers. The innermost layer is the stratum basale and is attached to the dermis by a basement 
membrane. In youth, this membrane is plump and healthy but with age it becomes flattened and as a result, there is less resistance to shearing forces and friction. The epidermis has no blood supply so oxygen and nutrients are delivered to it via a process of diffusion from the capillaries in the dermis. The layers of epidermis closest to the dermis receive most nutrition and the amount reduces the closer the layers become to the skin surface. The outermost layer of the epidermis is the stratum corneum which is essentially made up of dead cells. These cells are continuously being shed in a process called desquamation and new skin cells develop from the dermis and push the epidermal layers upwards. This is an ongoing process with skin turnover taking approximately 4 weeks on average, though this may be substantially longer as ageing progresses.

The dermis is a form of connective tissue which contains a number of important structures including nerve endings, blood and lymphatic vessels, hair follicles and sweat glands. It is separated from the epidermis by the basement membrane whose composition decreases with age. With ageing, there is also a reduction in collagen and elastin, which provide the skins strength and elasticity. There may be diminished capillary blood flow and less oil produced by the sebaceous glands, making for drier skin. Falling oestrogen levels in women also strongly affect skin integrity (Farage et al 2013). These factors combined serve to make the skin more vulnerable to friction and shearing.

The subcutaneous layers of skin consist of fat and connective tissues. As the ageing dermis loses its healthy properties, so too does the subcutaneous layer, becoming thinner and less resistant to trauma. The looser connection between the dermis and subcutaneous layer means that any bleeding which does occur is more difficult to control and consequently large haematomas may occur (see figure 2. Figure 2 - to be reproduced by EN). Ultimately, the level of trauma necessary to injure the skin is far less than that necessary to injure younger, healthier skin. 


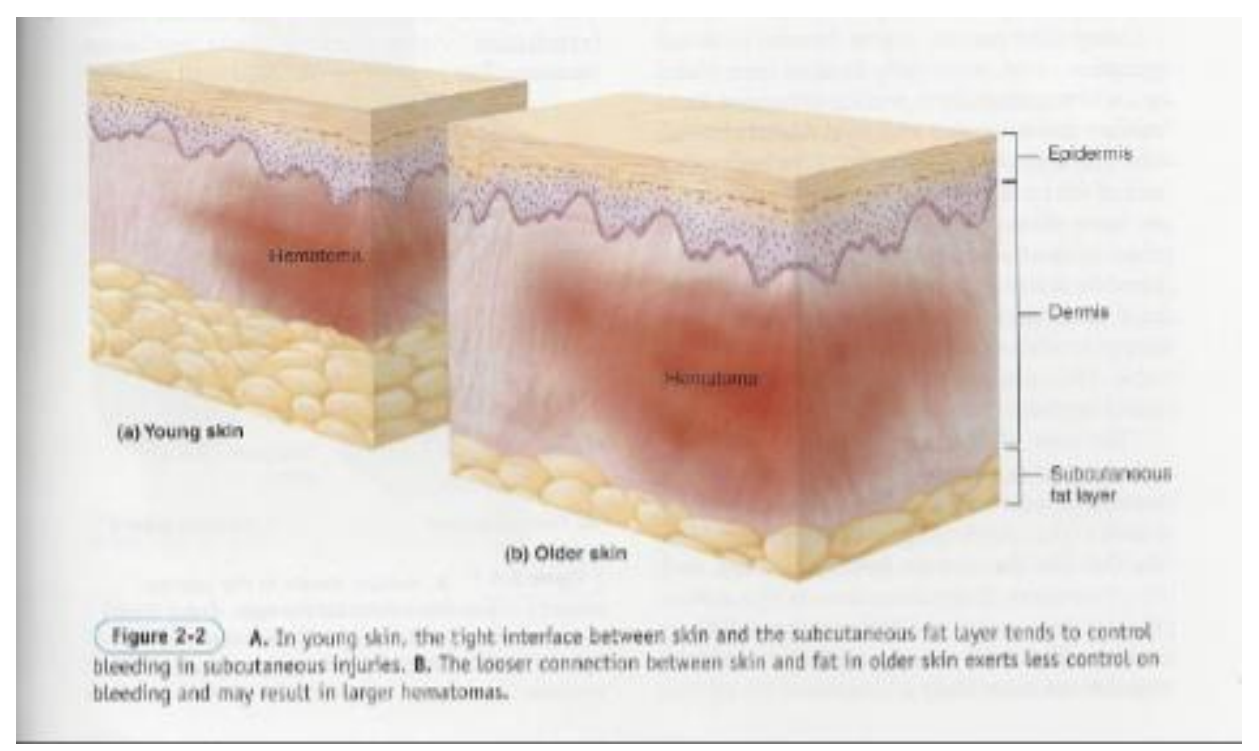

Figure 2 American Geriatric Society

Time out - think about patients you have seen with skin tears. In which areas did your patients sustain their injury?

The neck and the dorsal aspects of the hands, in particular, are considered to be areas of the body which age more rapidly, due in part to their greater exposure to the damaging effects of sun. These areas have greater susceptibility to loss of the fatty layers and consequently may also be vulnerable to skin tears along with the forearms and pre-tibial area. Hebert (2016) asserts that $70-80 \%$ of skin tears occur on the hands and arms and that most are sustained during the hours between 0600-1100 or 1500-2100 hours when greater physical activity generally takes place.

Timeout - Now list the functions of the skin and why it is important to have intact skin.

\section{Functions of the skin}

The skin has many important functions including protection and sensation; immunity; synthesis of vitamin D; temperature regulation; excretion of water and urea, and facilitation of movement and growth via its elastic properties. Therefore, it is important that skin remains intact and in cases of trauma, that appropriate management encourages rapid healing and recovery. 


\section{Appearance of skin tears}

Skin tears have very characteristic appearances (see figure 4 STAR criteria) and often present with some skin loss or with an obvious skin flap, or both. Stephen-Haynes (2016) states that there are two grades of skin tear - partial thickness skin tears and full thickness. The former results in separation of the epidermis from the dermis, the latter in separation of the epidermis and dermis from the underlying structures such as tendon or bone. Visual inspection will help to determine this.

If a patient presents with a dressing in place, it is important to try and establish the direction of the flap in order to remove the dressing in the least traumatic way. Health care professionals should be encouraged to either document or use a directional arrow on the dressing itself to indicate the direction of the flap and the best way to remove the dressing (see Figure 3 Figure 3 to be reproduced by EN).

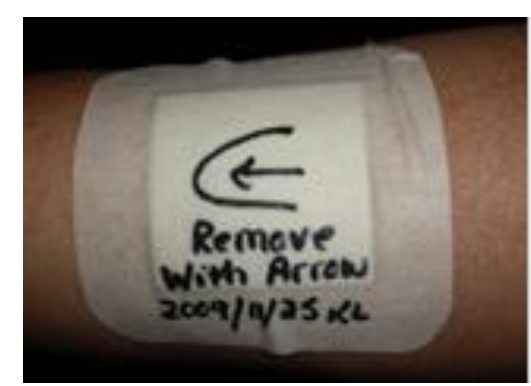

Figure 3 From Le Blanc et al

\section{Assessment of skin tears.}

Wound inspection and documentation should include the following:

- A description of the anatomical site of the wound.

- A history of the mechanism of injury and time injury sustained.

- Dimensions of the wound

- The degree of viable versus non-viable tissue, including flap necrosis. 
- Any exudate and type e.g., haemoserous fluid, blood

- Presence of haematoma

- Condition of the surrounding skin (swelling, maceration, induration, infection)

- Possibility of wound edge approximation or not

A pain assessment should also take place using an appropriate pain scale and be recorded and acted upon before working on the wound itself. The All Wales Tissue Viability Forum (2015) consider the assessment incomplete if due attention is not given to underlying disease processes such as diabetes and peripheral vascular disease which may have contributed to the injury and which may impact on the healing process. Benbow (2016) asserts that other factors such as smoking, ageing, nutrition, mobility and stress must also be taken into account during assessment.

A number of skin tear classification systems exist and it is good practice to adopt such a system. The most well-known validated systems are the Payne-Martin Classification (Payne and Martin 1993) and the Skin Tear Classification System, commonly known as STAR (Carville et al 2007). The Payne-Martin system (table 2) describes 3 categories of skin tear based on whether there is no tissue loss (category I), partial tissue loss (category II) or complete tissue loss (category III). Categories I and II are further subdivided (see table 2). The STAR classification (figure 2) provides 5 categories of skin tear based on appearance. Key factors in assessment include presence or absence of a flap (also known as a pedicle); colour of the skin and flap itself, and whether or not the edges of the tear can be realigned to normal anatomy.

\begin{tabular}{|l|l|}
\hline Category I: No tissue loss & $\begin{array}{l}\text { Ia) Linear type } \\
\text { Ib) Flap type }\end{array}$ \\
\hline Category II: Partial tissue loss & $\begin{array}{l}\text { Ila) Scant tissue loss less than } 25 \% \\
\text { Ilb) Moderate to large tissue loss over } 25 \%\end{array}$ \\
\hline Category III: Skin tear with complete tissue loss & \\
\hline
\end{tabular}




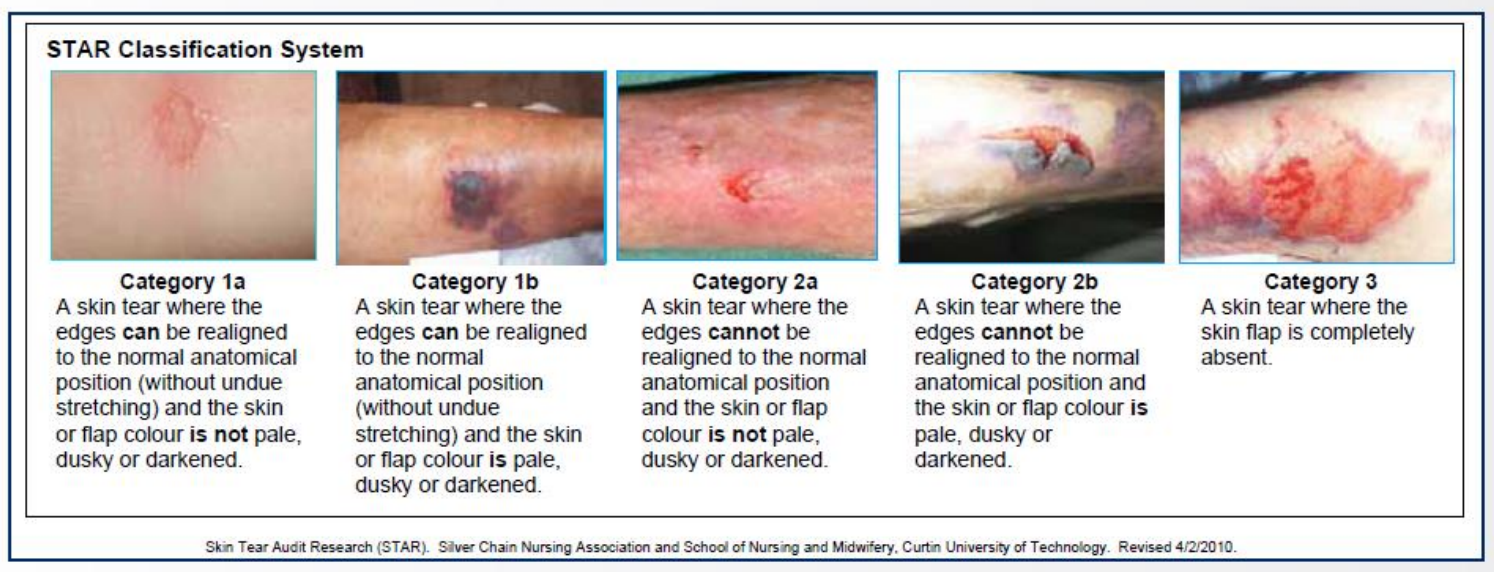

Figure 3. STAR classification

\section{Initial management of the wound}

The general principles of wound management are the same as for other wounds and include haemorrhage control; wound cleansing; gentle removal of haematoma, and tetanus prophylaxis if required. (See figure 5).

Time out: which patients do you think would require tetanus vaccination and what form would this take

\begin{tabular}{|c|c|c|c|}
\hline \multirow[t]{2}{*}{ IMMUNISATION STATUS } & CLEAN WOUND & TETANUS-PRONE WOUND & \\
\hline & Vaccine & Vaccine & $\begin{array}{l}\text { Human tetanus } \\
\text { immunoglobulin }\end{array}$ \\
\hline $\begin{array}{l}\text { Fully immunised, i.e. has } \\
\text { received a total of five } \\
\text { doses of vaccine at } \\
\text { appropriate intervals }\end{array}$ & None required & None required & $\begin{array}{l}\text { Only if high risk } \\
\text { (see p 379) }\end{array}$ \\
\hline $\begin{array}{l}\text { Primary immunisation } \\
\text { complete, boosters } \\
\text { incomplete but up to date }\end{array}$ & $\begin{array}{l}\text { None required (unless } \\
\text { next dose due soon and } \\
\text { convenient to give now) }\end{array}$ & $\begin{array}{l}\text { None required (unless } \\
\text { next dose due soon and } \\
\text { convenient to give now) }\end{array}$ & $\begin{array}{l}\text { Only if high risk } \\
\text { (see p 379) }\end{array}$ \\
\hline $\begin{array}{l}\text { Primary immunisation } \\
\text { incomplete or boosters } \\
\text { not up to date }\end{array}$ & $\begin{array}{l}\text { A reinforcing dose of } \\
\text { vaccine and further } \\
\text { doses as required to } \\
\text { complete the } \\
\text { recommended schedule } \\
\text { (to ensure future } \\
\text { immunity) }\end{array}$ & $\begin{array}{l}\text { A reinforcing dose of } \\
\text { vaccine and further } \\
\text { doses as required to } \\
\text { complete the } \\
\text { recommended schedule } \\
\text { (to ensure future } \\
\text { immunity) }\end{array}$ & $\begin{array}{l}\text { Yes: one dose of human } \\
\text { tetanus immunoglobulin } \\
\text { in a different site }\end{array}$ \\
\hline $\begin{array}{l}\text { Not immunised or } \\
\text { immunisation status not } \\
\text { known or uncertain }\end{array}$ & $\begin{array}{l}\text { An immediate dose of } \\
\text { vaccine followed, if } \\
\text { records confirm the } \\
\text { need, by completion of a } \\
\text { full five-dose course to } \\
\text { ensure future immunity }\end{array}$ & $\begin{array}{l}\text { An immediate dose of } \\
\text { vaccine followed, if } \\
\text { records confirm the } \\
\text { need, by completion of a } \\
\text { full five-dose course to } \\
\text { ensure future immunity }\end{array}$ & $\begin{array}{l}\text { Yes: one dose of human } \\
\text { tetanus immunoglobulin } \\
\text { in a different site }\end{array}$ \\
\hline
\end{tabular}

Figure 5. Source: Public Health England, The Green Book, page 381 
It is important that any skin flap is approximated and returned as closely as possible to its normal anatomical position. This can be achieved with a gloved finger or a non-traumatic tool such as a cotton bud, dampened in water or saline to prevent cotton wool fragments adhering to the wound. If this proves difficult an attempt should be made to rehydrate the skin, which may make the procedure easier by making the flap more pliable. This can be done by placing a moist non-woven swab over the area for up to 10 minutes (Le Blanc et al 2016).

Wounds that are assessed as being full-thickness should be referred to a specialist according to local policy and consideration should also be given to referring wounds where there is significant bleeding or haematoma formation (Stephen-Haynes and Carville 2011)

Time out: Recall the stages of the wound healing process.

The main aims of treatment are to preserve the skin flap and protect the surrounding skin, as well as to promote healing and prevent infection. Wound healing by primary intention is said to progress through four different stages which are not necessarily sequential but often overlap. These are: haemostasis, inflammation, proliferation and maturation. This process occurs in wounds that are simple and involve no loss of tissue. However, in wounds where tissue loss is present, this process is altered and is known as wound healing by secondary intention (Brown 2015). It is not within the scope of this article to further expand on wound healing.

Time out: Undertake your own research into the different types of wound healing. 


\section{Wound management and dressing choice}

Any wound dressing should be suitable for the wound environment and should promote the healing process. Due to the fragile nature of the skin in this injury, the use of sutures or surgical staples is generally precluded. Instead an atraumatic wound dressing should be applied and left undisturbed for as long as considered practicable or desirable, based on the wound assessment and presence of exudate. The dressing should be chosen for its ability to maintain a moist wound environment and to protect the surrounding skin. Patient comfort and ease of removal are also important factors. Exudate may be heavier where the limb is already oedematous e.g. in patients with chronic heart failure, and a holistic assessment should determine whether the underlying disease process is sufficiently wellcontrolled. In the presence of a dusky or darkened skin flap, suggesting possible vascular compromise, a dressing change and reassessment should take place within 24-48 hours (Wounds UK, 2012).

Based on the Payne-Martin classification, Le Blanc et al (2008) proposed a comprehensive guide to dressing selection. Control of bleeding is fundamental to this. For most skin tears, they advocated the use of silicone or low-tack foam dressings with alginate underneath if bleeding is present. Absorbent, clear acrylic dressings can also be used. Le Blanc et al advocated leaving acrylic dressings intact for 21 days, except for heavily exuding wounds, as these dressings are designed to be left in place for extended time periods and early removal could have a deleterious effect on healing. For category 1 skin tears they suggested that surgical glue may also be an option but emphasised that all dressing choices are based on a thorough assessment.

In a more recent international consensus statement on behalf of the International Skin Tears Advisory Panel, Le Blanc and Baranoski (2016) suggest that research around adhesive strips (e.g. Steristrips) is "outdated" and that expert opinion and consensus suggests that these are no longer the treatment of choice. They categorically assert that, "best practice supports. the use of hydrogel, alginate, lipido-colloid-based mesh and foam dressings, soft silicone, foam, or non-adherent dressings, applied depending on wound characteristics". Other recent literature (Hebert, 2016) concurs with the range 
of dressings described above but in contrast, continues to advocate adhesive strips and petroleumbased ointments and gauze as options. Whilst Hebert provides a rationale for the use of most of the dressings mentioned in her article, no rationale is provided for these two specific treatment options, perhaps supporting the consensus view that their use is not best practice. A further recent UK report by experts in the field supports the international consensus (Stephen-Haynes and Deeth 2016).

Time out: consider the range of dressings that are available to you in the workplace. Do you know their properties and how to select an appropriate dressing? If possible, go online and consult Edwards et al's comprehensive Wound Dressing Guide (2013), to further enhance your knowledge. This guide is available at https://cms.qut.edu.au/ data/assets/pdf file/0003/451767/Book2-wound-dressingguide.pdf and much subsequent information in this article regarding dressings is derived from this useful guide.

Alginate dressings (e.g. Kaltostat) are manufactured from seaweed and possess properties that can absorb significant amounts of fluid via hydrophilic gel formation. They are dry when applied to a wound and expand, becoming more gel-like as they draw fluids in. This not only helps 'clear out' the wound but also helps maintain a moist wound environment, and, to an extent, protects it from bacteria, thus lowering the risk of infection. Therefore, alginate dressings are useful for exuding wounds but not dry or necrotic wounds. In addition, alginates usually possess haemostatic properties because of calcium within the dressing, which helps blood coagulation. Their use is also recommended in infected wounds where antibiotic cover is in place, however they require a secondary dressing to hold the alginate in situ and to absorb excess exudate. Foam dressings (e.g. Lyofoam) are often used in combination with alginates because of their ability to absorb excess exudate, provide additional protection to the injured area and because they can conform to uneven body surfaces.

Hydrogel dressings are designed to moisturise wounds and promote autolytic debridement, that is, to assist the wound to naturally separate and shed devitalised tissue from healthy tissue. The dressing 
encourages the body's own enzymes to carry out this process. There are different presentations of hydrogels including tubes of gel, gel sheets and gel-impregnated dressings. Gel sheets are suitable for flat wounds such as a skin tear. They should not be combined with foam dressings however as the foam will absorb the gel. Thus hydrogels are suitable for drier rather than heavily exuding wounds but will still often require a secondary dressing to secure them in place and may also cause maceration of the surrounding healthy skin. This can be minimized by the use of barrier cream on the surrounding area.

Silicone dressings are considered suitable for skin tears as they provide a wound contact layer yet are atraumatic on removal. They may be used on infected wounds though appropriate antibiotic cover must be in place. Again, there are a variety of dressing presentations including foams, sheets and semitransparent films. Sheet-type dressings do not have to be trimmed to wound size and can safely lie on healthy skin, facilitating easier removal. They are reputedly cost-prohibitive, cannot be used on bleeding wounds and may also require a secondary dressing.

Lipido-colloid dressings are newer to the market and are described as combining lipido-colloid particles in either a non-occlusive fine mesh or within a foam dressing which is said to promote healing in a moist environnent by encouraging fibroblast proliferation and collagen production (Urgo Medical, 2015). In their clinical review of these dressings, White et al (2011) further explain the physiological effects of these dressings on wound healing and support the notion of atraumatic removal.

Finally, hydrocolloids such as Duoderm or Granuflex are no longer recommended because their adhesive may compromise fragile skin on removal. All dressings should promote moist wound healing as it provides favourable conditions for the pathophysiological processes of wound healing and reduces wound pain by keeping nerve endings moist.

Time out: consider the management of skin tears within your own clinical environment. Does it reflect current best evidence? If not, how do you think you could influence this? 


\section{Complications of skin tears}

Infection is clearly a potential sequela of skin tears and a study by Keeton et al (2015) has demonstrated that having the least chance of infection is a key outcome, not just for clinicians, but for patients themselves. In its presence, careful consideration should be given as to whether topical or systemic antibiotics are required, bearing in mind that indiscriminate use of antibiotics is not recommended. Infection, however, is likely to delay healing time and may potentially progress to cellulitis or sepsis, with all that implies. Other complications include delayed healing in the presence of oedema or peripheral vascular disease. Patient education is vital in preventing complications and should include advice about rest versus exercise; limb elevation; analgesia, nutrition and smoking cessation. As a minimum, patients with skin tears are likely to suffer pain and poor mobility, compromising their quality of life and possibly leading to both physical and mental distress (Le Blanc et al 2016). To this end, Le Blanc and colleagues, as part of the International Skin Tear Advisory Panel (ISTAP), have developed a tool kit for the prevention, assessment and management of skin tears. Le Blanc et al further suggest that the management and experience of skin tears is underappreciated both in the literature and in clinical practice.

\section{Conclusion}

Skin tears are prevalent in the elderly population and their management may be adversely affected by co-existing medical conditions including, but not limited to, diabetes, infection and peripheral vascular disease. Because of their propensity to induce pain and distress, it is better to adopt a strategy of skin tear prevention rather than cure. All healthcare professionals should be aware of risk factors and should use patient education and appropriate referral systems to reduce the prevalence, or if not possible, to enhance the healing process and prevent complications. It is vitally important that clinicians understand the nature and appropriateness of the dressings they use for skin tear management and keep up-to-date with best evidence from experts in the field. 
References

All Wales Tissue Viability Forum. (2015) Prevention and management of skin tears. [online] Available at http://www.welshwoundnetwork.org/files/8314/4403/4358/content 11623.pdf Accessed 3 Jan 2017

Baranoski S. (2005) Meeting the challenge of skin tears. Advanced Skin Wound Care. 18, 2,74-5.

Benbow M. (2016) Best practice in wound assessment. Nursing Standard. 30, 27, 40-47

Bianchi J. (2012) Preventing, Assessing and Managing Skin Tears. Nursing Times. 108, 13, 12-16

Brown A. (2015) Phases of the wound healing process. Nursing Times. 111, 46, 12-13

Carville K, Lewin G, Newall $\mathbf{N}$ et al. (2007) STAR: a consensus for skin tear classification. [Online] Available at http://www.woundsaustralia.com.au/journal/1501 03.pdf Accessed 3 Jan 2017

Clothier A. (2014) Assessing and managing skin tears in older people. [online] Available at http://www.independentnurse.co.uk/clinical-article/assessing-and-managing-skin-tears-in-olderpeople/63411/Accessed 3 Jan 2017

Edwards H, Gibb M, Finlayson K et al. (2013) Wound dressing guide. [online] Available at https://cms.qut.edu.au/ data/assets/pdf file/0003/451767/Book2-wound-dressing-guide.pdf Accessed 3 Jan 2017

Farage M, Miller K, Elsner, P et al. (2013) Characteristics of ageing skin. Advances in Wound Care. 2, $1,5-10$

Hebert G, (2016) No more skin tears. Wound Care Advisor. 5, 5, 28-32

Keeton H, Crouch R, Lowe K. (2015) What is important to patients in wound management. Emergency Medicine. 32, 153-154. doi:10.1136/emermed-2013-202807

Le Blanc K, Baranoski S. (2011) Skin tears: state of the science: Consensus statements for the prevention, prediction, assessment and treatment of skin tears. [online] Available at http://www.skintears.org/Consensus-Statements/Statement9.aspx Accessed 3 Jan 2017

Le Blanc K, Christensen D, Orsted $\mathrm{H}$ et al. (2008) Best practice recommendations for the prevention and treatment of skin tears. Wound Care Canada. 6, 1, 14-30

Le Blanc K, Baranoski S, Christensen D et al. (2016) The art of dressing selection: a consensus statement on skin tears and best practice. Advances in Skin and Wound Care. 29, 1, 32-46

Morgan T. (2015) Are your wound management choices costing you money? Journal of Community Nursing. 29, 4, 17-20

Mulligan S, Scott L, Prentice J et al. (2009) Wounds West Wound Prevalence Survey State-wide Report. [online] Available at https://www.whia.com.au/whwp/wp-content/uploads/2015/05/WWWPS09State-Report-Final.pdf Accessed 3 Jan 2017

Mulligan S, Prentice J and Scott L. (2011) Wounds West Wound Prevalence Survey State-wide Overview Report. [online] Available at https://www.whia.com.au/whwp/wpcontent/uploads/2015/05/WWWPS2011-State-wide-Report-Overview-Final.pdf Accessed 3 Jan 2017

Payne R and Martin M. (1993) Defining and classifying skin tears: need for a common language. Ostomy Wound Management. 39, 5, 16-26

Pyer M, Campbell J, Ward A et al. (2015) Journal of Paramedic Practice 7, 2, 68 - 72 
Stephen-Haynes J, Carville K. (2011) Skin tears made easy. [online] Available at http://www.woundsinternational.com/media/issues/515/files/content 10142.pdf Accessed 3 Jan 2017

Stephen-Haynes J, Deeth M. (2016) The prevention, assessment and management of skin tears. Practice Nurse. 46, 6, 32-37

Stephen-Haynes J, Callaghan R, Berthell E et al. (2011) The assessment and management of skin tears in care homes. British Journal of Nursing. 20, 11, 10-23

Public Health England. (2013) Tetanus: The Green Book, chapter 30 p367-384 [online] Available at https://www.gov.uk/government/publications/tetanus-the-green-book-chapter-30 Accessed 3 Jan 2017

Urgo Medical. (2015) Presentation of TLC - an exclusive wound management solution. [online] Available at www.urgo.co.uk/205-tlc-technology Accessed 3 Jan 2017

White R, Cowan T, Glower D. (2011) Supporting evidence-based practice: a clinical review of TLC technology. [online] Available at http://www.urgomedical.com/wpcontent/uploads/TLC\%20evidence\%20review.pdf Accessed 3 Jan 2017

Wounds UK. (2012) Best Practice Statement. Care of the Older Person's Skin. (2 ${ }^{\text {nd }}$ ed) [online] Available at http://www.woundsinternational.com/media/issues/622/files/content 10608.pdf Accessed 3 Jan 2017 
ANSWERS TO LABELLING DIAGRAM OF THE SKIN

1 Stratum basale

2 Stratum spinosum

3 Stratum granulosum

4 Stratum lucidum

5 Stratum corneum

6 Dermal papillae

7 Subpapillary vascular plexus

8 Eccrine sweat gland

9 Sebaceous gland

10 Hair follicle

11 Cutaneous vascular plexus

12 Adipose tissue (fat)

13 Hair follicle receptor

14 Pacinian corpuscle

15 Sensory nerve fibre

16 Hypodermis (subcutaneous layer)

17 Reticular layer

18 Papillary layer

19 Hair shaft

20 Arrector pili muscle

21 Meissner's corpuscle 
